The gist of his argument lies in his assertion, that " if a true pound, as determined at London, were carried to the North Pole, it would weigh more than a pound."

Now, since the determination of a pound is actually effected by making it a copy of a standard so that they shall counterpoise each other in vacuo, it is strictly independent of locality.

The standards actually employed for this purpose, for example, the authorised copies of the principal standard pound which have been sent to various countries, have been made as nearly identical in mass as skilled workmen could make them, and have been sent at random to different latitudes.

Similar remarks apply to the weights in a chemist's box. Surely it is not seriously proposed that the chemist should file them down to accommodate them to the increase of gravity, when he takes them from London to Edinburgh.

Where should we find ourselves, if the makers of chemists' weights endeavoured to make them of different masses, according to the places where they were to be used?

Fortunately, this has never been attempted; and since all parts of the world are in possession of practically identical standards of mass, under the name of standard pound or standard kilogramme, and tolerably accurate copies of these and their fractional parts are in everybody's hands, why not acknowledge them as standards of mass, which they are in point of fact, although, according to the theory which I am combating, they ought not to be?

Those who hold that theory must choose between two evils :they must either make the pound a unit of force, in which case they must file or load their weights as they go from place to place (this seems to be the alternative which W. M. W. chooses); or they must accept the gravitating forces of equal pieces of metal as nominal units of force at the different localities where these pieces of metal may happen to be, although these forces are really not equal. This latter alternative, which gives a variable unit of force, has been commonly adopted till recently, and a variable unit of mass has been conjured up to suit it.

If our spring-balances were as accurate as our standard weights, W. M. W.'s idea would be practicable. The equality of two forces at different places could then be very directly tested; but, in fact, the most accurate means we possess of making such a comparison consists in a double process, a weighing with the ordinary balance, combined with a difficult and less accurate pendulum-comparison. Inasmuch then as ease and accuracy of comparison is the first essential of a scientific standard, I submit that the world is right in employing standard pounds of equal mass and not standard pounds of equal gravitating force.

Much confusion arises from using the word zeright in a connection which leaves it doubtful whether mass or gravitating force is meant. I trust you will keep your columns open for the further discussion of this question, as it much needs ventilation.

Belfast, January in J. D. EVERETT

The Tails of Comets, the Solar Corona, and the Aurora considered as Electric Phenomena

IN reference to a letter from Mr. Bedford, Ph.D., published in your last number, allow me to state-

I. That I had never seen or heard of Dr. Bedford's theories.

2. That, judging from the extract given in his letter, Dr. Bedford has not published anything analogous to the electrical hypothesis which I have put forward. In his letter he has misquoted and made omissions to the extent of one-half the heading, in order, I suppose, to avoid the very mention of the word electricity, which, on the other hand, is the very substance of my postulate.

Owens College, Jan. I7

\section{Apparent Size of the Moon}

From almost any place in the balcony of St. James's Hall, at an evening performance, one may find in the coronets of gasjets, furming one or more of the arches across the roof, corroboration of what i wrote in NA'TURE of May I2, 1870 (vol. ii. p. 27). The nearest or first coronet, and the two next, observe a gradation of increase in apparent magnitude, as they should do. But the rest, which (unlike those three) descend towards the horizon, and should, nevertheless, observe a gradation of increase, are apparently all of a size. I call attention to this "unconsidered trifle" as having the full force of a very elaborate experiment.

Ilford, Jan. 7.

\section{Atmospheric Currents}

THE following is part of a letter signed "G." in NATURE of 6th October, I870:-

"It is very important to obtain correct and copious data regarding the atmospheric currents between say 5,000 feet and five miles above the level of the sea, and especially at various points on and near the equator, and at about $30^{\circ}$ to $32^{\circ}$ North and South latitudes. Within these limits the rain-bearing currents of the atmosphere move. If self-registering meteorological instruments were placed permanently upon several of the leading mountain ranges of the world, and their records copied at stited intervals, we should obtain valuable data for determining the direction, velocity, and magnitude of the controlling atmospheric currents of the globe."

This suggestion is most valuable, but it would involve a source of error that would be difficult to allow for. Most mountain ranges occupy so extensive an area that they have their own local climates, and indications on such ranges would consequently not give accurate information about the currents where they are not modified by such influences. The most valuable information will be obtained from the most isolated mountains. The most isolated mountains of sufficient height, within sufficiently easy reach of us, are Etna and Teneriffe. Etna is in the variables, and Teneriffe in the trade-winds.

I do not, however, agree with the following suggestion, that more valuable observations still might be obtained by means of captive balloons. Balloons cannot be used in stormy weather and they are also subject to the great disadvantage, that they tell nothing about barometric fluctuations : because the height of a balloon above the earth can be known only from the barometer, and consequently there is no way of ascertaining the indications of the barometer at a known height. It is not at all certain that the barometric curves at the summit and at the base of Etna or Teneriffe would present any close correspondence. Sets of barometrical and other meteorological observations taken for sufficiently long periods at the summit and at the base of such mountains would be probably the most valuable of all data for meteorological science in its present state.

Old Forge, Dunmurry, Co. Antrim, Jan. I4

\title{
THE AMERICAN ECLIPSE EXPEDITION
}

THAT portion of the American Eclipse Expedition which was stationed at Xeres was favoured by weather which enabled the observers to examine the Corona during the whole period of totality, and with some results of interest; an informal account of a part of which the kindness of Professor Winlock enables me to lay before your readers.

The party was in charge of Professor J. Winlock, and stationed in an olive grove about a mile from the city, the property of Mr. Davies, of Xeres, to whom all the members of the expedition are indebted for continual aid and kindness. The observations for the determination of longitude, latitude, and times of contact were conducted by Assistant G. W. Dean, of the Coast Survey, aided by Captain Ernst, of the U.S. Engineers, and by Mr. Gannett, of the Harvard College Observatory.

Their labours were facilitated by the courtesy of the Director of the neighbouring Observatory of San Fernando, with which telegraph connection was established, and the results attained will be found in full in their official report.

Besides the instruments of precision, the party was provided with four equatorial telescopes of from six to eight inches aperture, driven by clockwork, and many smaller ones. One of the largest telescopes carried an objective specially corrected for actinic rays, with which, and a companion instrument, photographs were taken during the totality and previous stages by Mr. Willard and his assistant.

In addition, a photographic telescope of upwards of thirty feet focus, placed horizontally, and receiving the solar rays from a heliostat, was used, in charge of $\mathrm{Mr}$. Gannett.

The accessories of the instruments were such as the previous experience of the observers (nearly all of whom had witnessed the eclipse of August I 869) suggested, and were too numerous for description here, though a means 